\title{
Hydrothermal synthesis of simonkolleite microplatelets on nickel foam graphene for electrochemical supercapacitors
}

\author{
S. Khamlich ${ }^{\mathrm{a}, *}$, A. Bello ${ }^{\mathrm{a}}$, M. Fabiane ${ }^{\mathrm{a}}$, B. D. Ngom ${ }^{\mathrm{b}}$, N. Manyala ${ }^{\mathrm{a}, *}$ \\ ${ }^{a}$ SARChI Chair in Carbon Technology and Materials, Institute of Applied Materials, Department of \\ Physics, University of Pretoria, Private Bag X20, Hatfield 0028, South Africa \\ b NANOAFNET, MRD-iThemba LABS, National Research Foundation,1 Old Faure road, Somerset \\ West 7129, South Africa
}

\begin{abstract}
Nickel foam-graphene (NF-G) was synthesised by chemical vapour deposition (CVD) followed by facial in situ aqueous chemical growth of simonkolleite $\left(\mathrm{Zn}_{5}(\mathrm{OH})_{8} \mathrm{Cl}_{2} \cdot \mathrm{H}_{2} \mathrm{O}\right)$ under hydrothermal conditions to form NF-G/simonkolleite composite. X-ray diffraction and Raman spectroscopy show the presence of simonkolleite on the NF-G, while scanning electron and transmission electron microscopies show simonkolleite micro-plates like structure evenly distributed on the NF-G. Electrochemical measurements of the composite electrode give a specific capacitance of $350 \mathrm{Fg}^{-1}$ at current density of $0.7 \mathrm{Ag}^{-1}$ for our device measured in three-electrode configuration. The composite also shows a rate capability of $\sim 87 \%$ capacitance retention at a high current density of $5 \mathrm{Ag}^{-1}$, which makes it a promising candidate as an electrode material for supercapacitor applications.
\end{abstract}

Keywords: Graphene. Composite structure. Simonkolleite. Supercapacitor

Corresponding authors: S. Khamlich, N. Manyala

Emails: skhamlich@gmail.com

ncholu.manyala@up.ac.za 


\section{Introduction}

The energy and power densities of energy storage devices need to be improved significantly to meet the growing power supply demand of a variety of applications such as cordless electric tools, hybrid electric vehicles, day-night storage, and industrial energy management [1]. In recent years, many researchers have focused on the development of electrode materials to increase the energy density of electrochemical capacitors (also known as supercapacitors), while retaining their intrinsic high power density. Furthermore, supercapacitors have generally used carbonaceous materials with a large surface area (e.g. carbon nanotubes [2], carbon [3] and graphene [4]) and transition metal oxides (e.g. $\mathrm{Co}_{3} \mathrm{O}_{4}$ [5,6], $\mathrm{NiO}$ [7], $\mathrm{RuO}_{2}$ [8], $\mathrm{SnO}_{2}$ [9], $\mathrm{MnO}_{2}$ [10], $\mathrm{V}_{2} \mathrm{O}_{5}$ [11], and so forth). Recently, graphene has been shown to be an effective material for constructing supercapacitor electrodes due to its large surface area, high mechanical stability and electrical conductivity $[12,13]$. Graphene electrode alone have been found to have specific capacitance of up to $135 \mathrm{~F} / \mathrm{g}[13,14]$. On the other hand, nanocomposites consisting of graphene and transition metal oxides have attracted wide attention in the field of supercapacitors due to the synergistic effect arising from the combination of the redox reaction of the metal oxides with the high surface area/conductivity of graphene, which improves the electrochemical performance [15,16]. This has been reported to be highly dependent on the quality and conductivity of the graphene [17].

Self-supporting graphene nanosheets (GNS), via chemical reduction of exfoliated graphite oxide, have shown great potential as flexible electrodes with excellent mechanical stiffness and strength $[18,19,20]$. However, in most cases, these GNS were assembled into macroscopic paper-like structures in a way that reduced the large accessible surface area of the two-dimensional (2D) GNS. This usually results from irreversible agglomeration and restacking of the individual GNS which hinders the potential applications of graphene materials in supercapacitor devices. The resulting GNS also exhibit inferior conductivity due to the abundant existence of defects and oxygen-containing chemical groups, and to numerous non-ideal contacts between the nanosheets. In addition, the strong $\pi-\pi$ interaction between GNS leads to severe aggregation and a considerable decrease in its specific surface area [21]. Both of these shortcomings seriously limit the performance of graphene-based supercapacitors, sensors and other devices. 
Chemical vapor deposition (CVD) is an alternative method for synthesizing a three dimensional (3D) network of graphene on a nickel foam template[22] which exhibits high conductivity compared with that of GNS $[23,24]$. This facilitates fast electron transport between the active materials and current collectors in supercapacitors [15,17]. Furthermore, CVD-grown 3D graphene networks have high conductivity due to the high intrinsic conductivity of defect-free graphene and the absence of inter-sheet junction resistance in this seamlessly continuous network [21]. In addition, the porous nature of this new graphene material offers a large specific surface area (up to $\sim 850 \mathrm{~m}^{2} / \mathrm{g}$ ) [22] and is suitable for the production of functional composites by filling the pores with metal oxide nanoparticles, polymers or other functional materials [25].

Similar to metal oxides, $\mathrm{Zn}_{5}(\mathrm{OH})_{8} \mathrm{Cl}_{2} \cdot \mathrm{H}_{2} \mathrm{O}$ (simonkolleite) is also electrochemically active as an electrode material for supercapacitors [26]. Most reports on simonkolleite deal with its bulk properties, with a net focus on understanding the surface atmospheric corrosion products on $\mathrm{Zn}$ plates [26,27]. Simonkolleite forms hexagonal microplatelet crystals with a perfect cleavage parallel to the (001) direction [28]. It is a soft compound with a Mohs hardness of $\sim 1.5$ and a specific gravity of 3.2 [29]. The crystal structure of the synthesis analogue of simonkolleite was reported by Nowacki \& Silverman [30] and Allmann [31]. Simonkolleite is electrically and chemically active due to the oxygen vacancies on its surface, as in the case of $\mathrm{ZnO}$. These vacancies may then function as n-type donors and thus significantly increase the material's conductivity [29].

In these work, we present a novel two-step approach for growing a nickel foam-graphene/ simonkolleite (NF-G/simonkolleite) 3D composite structure for electrochemical supercapacitors.

\section{Experiments and methods}

Growth of graphene on nickel foam

Nickel foams (Alantum, Munich, Germany), $420 \mathrm{~g} \mathrm{~m}^{-2}$ in a real density and $1.6 \mathrm{~mm}$ in thickness, was used as 3D scaffold templates for the CVD growth of graphene. It was cut into pieces of $1 \times 2 \mathrm{~cm}^{2}$ and placed in a quartz tube of outer diameter $5 \mathrm{~cm}$ and inner diameter 4.5 
$\mathrm{cm}$. The precursor gases were $\mathrm{CH}_{4}, \mathrm{H}_{2}$ and $\mathrm{Ar}$. The nickel foam was annealed at $800{ }^{\circ} \mathrm{C}$ in the presence of $\mathrm{Ar}$ and $\mathrm{H}_{2}$ for $20 \mathrm{~min}$, before the introduction of the $\mathrm{CH}_{4}$ gas at $1000{ }^{\circ} \mathrm{C}$ (Fig. 1). The flow rates of the gases $\mathrm{CH}_{4}, \mathrm{H}_{2}$ and $\mathrm{Ar}$ were 10, 10 and $300 \mathrm{sccm}$, respectively. After 15 min of deposition, the sample was rapidly cooled by pushing the quartz tube to a lower temperature region.

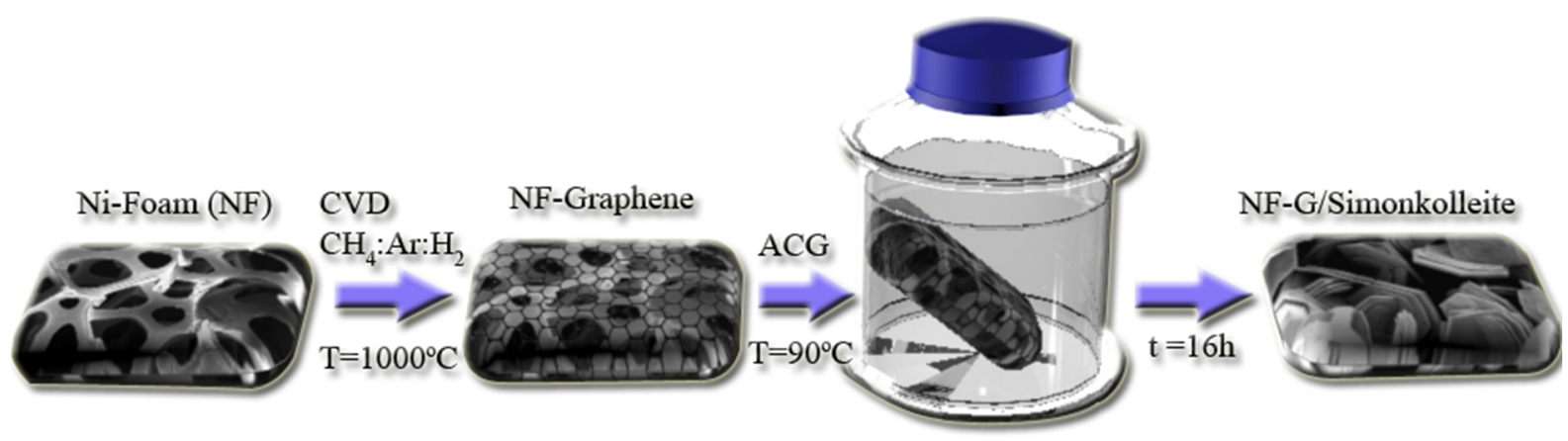

Figure 1: $\quad$ Synthesis process scheme of the NF-G/simonkolleite composite

Growth of simonkolleite on garaphene/nickel foam

Simonkolleite microplatelets $\left(\mathrm{Zn}_{5}(\mathrm{OH})_{8} \mathrm{Cl}_{2} \cdot \mathrm{H}_{2} \mathrm{O}\right)$ were deposited directly on the NF-G using the aqueous chemical growth (ACG) technique (Fig. 1). A solution containing zinc nitrate hexahydrate $\left(\mathrm{Zn}\left(\mathrm{NO}_{3}\right)_{2} \cdot 6 \mathrm{H}_{2} \mathrm{O}\right)$, sodium chloride $(\mathrm{NaCl})$ and hexamethylenetetramine (HMT) $\left(\mathrm{C}_{6} \mathrm{H}_{12} \mathrm{~N}_{4}\right)$ was used for the deposition of simonkolleite plate-like structures. A $100 \mathrm{ml}$ bottle with autoclavable screw cap was filled with an equimolar $(0.1 \mathrm{M})$ aqueous solution of $\mathrm{Zn}\left(\mathrm{NO}_{3}\right)_{2} \cdot 6 \mathrm{H}_{2} \mathrm{O}$, HMT and $\mathrm{NaCl}$. Subsequently, the NF-G samples fixed on glass slides were immersed in the solution and subjected to hydrothermal treatment at $90{ }^{\circ} \mathrm{C}$ for $16 \mathrm{~h}$. Thereafter, the autoclave was allowed to cool down to ambient temperature. The final NF-G/ simonkolleite composite was obtained after washing and drying. The formation of $\mathrm{Zn}_{5}(\mathrm{OH})_{8} \mathrm{Cl}_{2} \cdot \mathrm{H}_{2} \mathrm{O}$ is considered to proceed competitively in the solution following the successive chemical reaction:

$$
\begin{aligned}
& \mathrm{C}_{6} \mathrm{H}_{12} \mathrm{~N}_{4}+6 \mathrm{H}_{2} \mathrm{O} \longrightarrow 6 \mathrm{HCHO}+4 \mathrm{NH}_{3} \\
& \mathrm{NH}_{3}+\mathrm{H}_{2} \mathrm{O} \longrightarrow \mathrm{NH}^{4+}+\mathrm{OH}^{-} \\
& \mathrm{NaCl}+\mathrm{H}_{2} \mathrm{O} \longrightarrow \mathrm{Na}^{+}+\mathrm{Cl}^{-}+\mathrm{H}_{2} \mathrm{O}
\end{aligned}
$$


$\mathrm{Zn}\left(\mathrm{NO}_{3}\right)_{2} \cdot 6 \mathrm{H}_{2} \mathrm{O}+\mathrm{H}_{2} \mathrm{O} \longrightarrow \mathrm{Zn}^{2+}+\mathrm{NO}^{6-}+7 \mathrm{H}_{2} \mathrm{O}$

$5 \mathrm{Zn}^{2+}+8 \mathrm{OH}^{-}+2 \mathrm{Cl}^{-}+\mathrm{H}_{2} \mathrm{O} \longrightarrow \mathrm{Zn}_{5}(\mathrm{OH})_{8} \mathrm{Cl}_{2} \cdot \mathrm{H}_{2} \mathrm{O}$

First, $\mathrm{C}_{6} \mathrm{H}_{12} \mathrm{~N}_{4}$ disintegrates into formaldehyde (HCHO) and ammonia $\left(\mathrm{NH}_{3}\right)$ as shown in Equation (1). Ammonia tends to disintegrate water to produce $\mathrm{OH}^{-}$anions (Equation 2). Secondly, sodium chloride disintegrates in water forming sodium cations and chloride anions (Equation 3). Furthermore, $\mathrm{Zn}\left(\mathrm{NO}_{3}\right)_{2} \cdot 6 \mathrm{H}_{2} \mathrm{O}$ disintegrates into zincate ion $\mathrm{Zn}^{2+}$ and nitrate $\mathrm{NO}^{3-}$ (Equation 4). Finally, $\mathrm{OH}^{-}$and $\mathrm{Cl}^{-}$anions react with $\mathrm{Zn}^{2+}$ cations to synthesize simonkolleite nanoplatelets $\left(\mathrm{Zn}_{5}(\mathrm{OH})_{8} \mathrm{Cl}_{2} \cdot \mathrm{H}_{2} \mathrm{O}\right)$ (Equation 5).

\section{Material characterization}

The structural characterization of the NF-G/simonkolleite composite was investigated by X-ray diffraction (XRD) using a Bruker D8 Advance X-ray diffractometer equipped with $\mathrm{Cu} \mathrm{K} \alpha$ radiation $(\lambda=1.5406 \AA)$, employing a scanning rate of $0.2^{\circ} \mathrm{s}^{-1}$ and $2 \theta$ ranges from $20^{\circ}$ to $70^{\circ}$. The Raman spectra were recorded using a WITEC-Alpha 300R Plus confocal Raman spectrometer (WITEC GmbH, Ulm, Germany). The excitation source was a $532 \mathrm{~nm}$ laser (2.33 eV, $1 \mathrm{~mW}$ power) through a numerical aperture of 0.9 and with $100 \mathrm{x}$ magnification. Morphological characterization was performed on a high-resolution Zeiss Ultra Plus 55 field emission gun scanning electron microscope (FE-SEM) operated at $2.0 \mathrm{kV}$. Transmission electron microscopy (TEM) micro-images and selected area electron diffraction (SAED) observations were carried out with a JEOL JEM-2100F microscope operated at $200 \mathrm{kV}$. The capacitive properties were investigated by the cyclic voltammetry $(\mathrm{CV})$ method using an Autolab PGSTAT Workstation 302 (ECO-CHEMIE, Metrohm Autolab BV) driven by the GPES software. The as-prepared NF-G/simonkolleite composite served as the working electrode, glassy carbon plate as the counter-electrode and $\mathrm{Ag} / \mathrm{AgCl}(3 \mathrm{M} \mathrm{KCl})$ as the reference electrode in $2.0 \mathrm{M} \mathrm{KOH}$ electrolyte. Electrochemical impedance spectroscopy (EIS) was performed in the frequency range of $100 \mathrm{kHz}$ to $10 \mathrm{mHz}$. 


\section{Results and discussions}

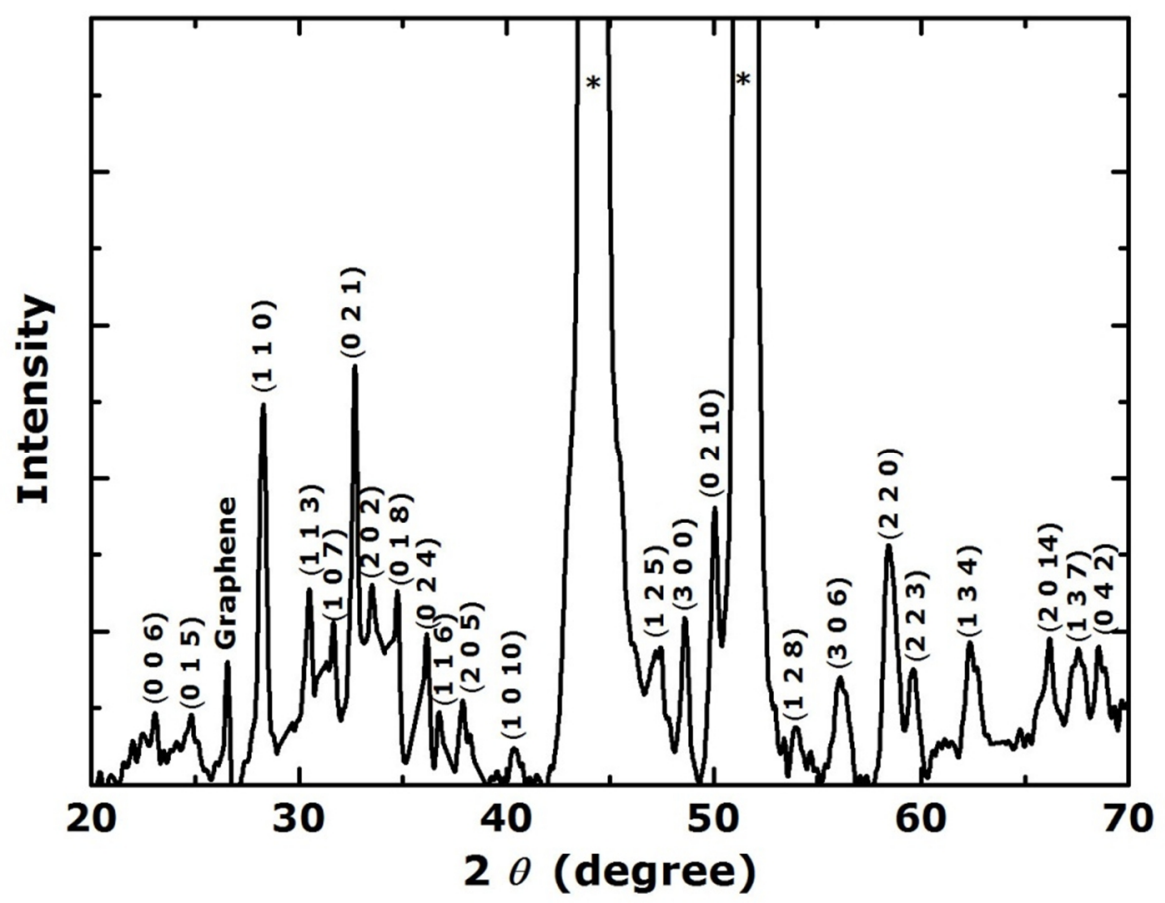

Figure 2: $\quad$ X-ray diffraction pattern of the NF-G/simonkolleite composite

Fig. 2 shows the XRD pattern of the as-synthesized NF-G/simonkolleite composite. The diffraction peaks in the $2 \theta$ range $20^{\circ}-70^{\circ}$ correspond to the characteristic reflections of simonkolleite material. The identification of all Bragg diffraction peaks confirms the crystallographic phase of the simonkolleite microplatelets and is ascribed to pure rhombohedral simonkolleite (JCPDS No. 07-0155) with lattice constants a and c of about $\sim 6.337 \AA$ and $\sim 23.643 \AA$ respectively and space group $R 3 m$. The relatively higher and sharper diffraction peaks observed are directly linked to the good crystallinity of the simonkolleite deposited on the NF-G. The strong diffraction peaks at the $2 \theta$ values $44.38^{\circ}$ and $51.71^{\circ}$ are associated with the Ni-foam and are indexed with an asterisk. In particular, the sharp peak at the $2 \theta$ value of $26.43^{\circ}$ corresponds to graphene formation [32], which indicates a good crystalline structure with an interlayer spacing of $0.339 \mathrm{~nm}$; this is consistent with the layer spacing of normal graphite.

Fig. 3 shows the Raman spectra of the NF-G and the NF-G/simonkolleite composite respectively. The Raman spectrum of NF-G shows two prominent peaks at $\sim 1591$ and $2726 \mathrm{~cm}^{-1}$, corresponding to the characteristic $\mathrm{G}$ and 2D bands of graphene [33]. The D band 


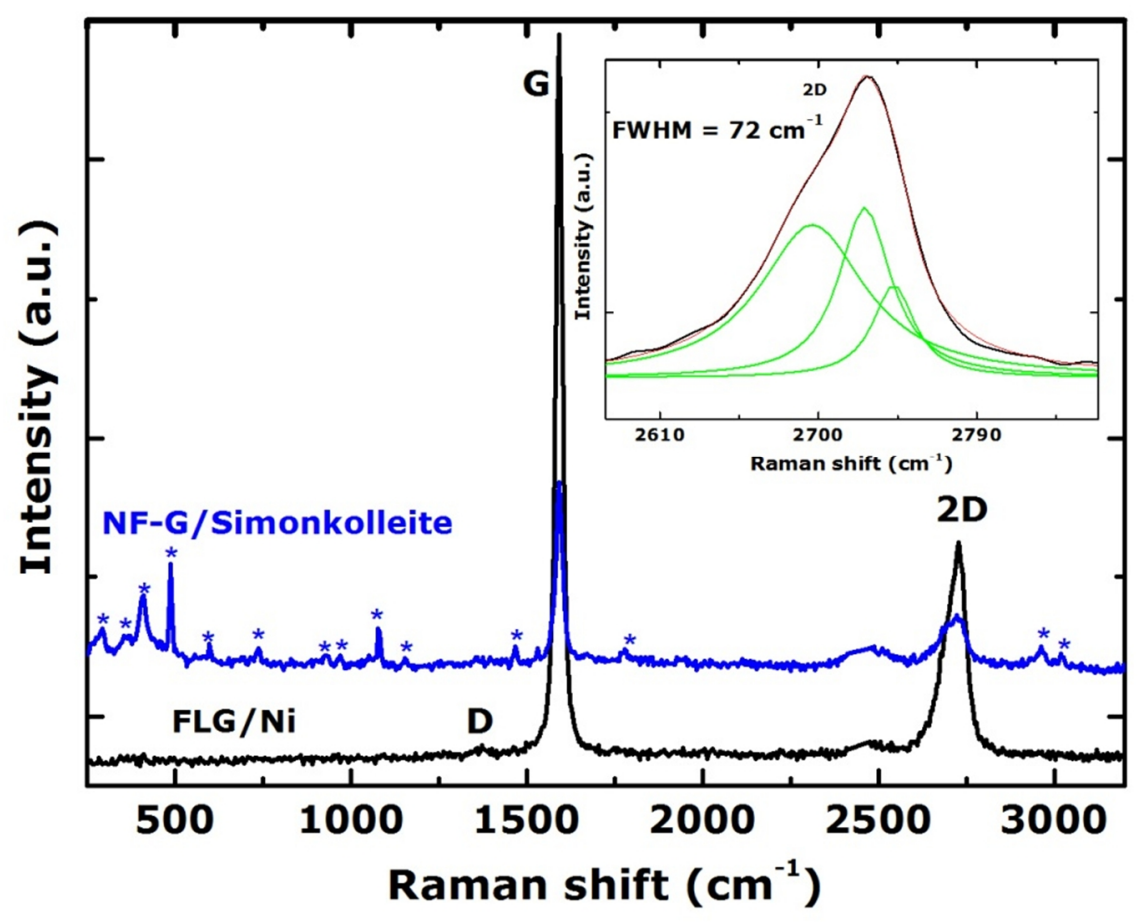

Figure 3: $\quad$ Raman spectra of the NF-G and the NF-G/simonkolleite composite, the inset shows a fitted lorentzian for $2 \mathrm{D}$ peak.

(usually at $\approx 1350 \mathrm{~cm}^{-1}$ ), which is attributed to the disordered graphitic carbon and its intensity, provides information about the density of defects in the as-grown graphene. The fact that this band is not visible in the spectrum signifies that the sample is free of defects. The intensity ratio $\mathrm{I}_{2 \mathrm{D}} / \mathrm{I}_{\mathrm{G}}(\sim 0.71)$ indicates that the as-grown graphene is mainly few layered (i.e. it has fewer than five layers) [34]. This is clearly distinguishable from the 2D signal as shown in the inset in Fig. 3 [35]. The Raman peaks at 400, 488 and $732 \mathrm{~cm}^{-1}$ indexed by an asterisk, which agree very well with what are found in the literature $\left(390,482\right.$ and $\left.730 \mathrm{~cm}^{-1}\right)$ [36], were assigned to $\mathrm{Zn}_{5}(\mathrm{OH})_{8}(\mathrm{Cl})_{2} \cdot \mathrm{H}_{2} \mathrm{O}$ (simonkolleite). A peak at $293 \mathrm{~cm}^{-1}$ was attributed to the $\mathrm{Zn}-\mathrm{Cl}$ bond and that at $358 \mathrm{~cm}^{-1}$ to $\mathrm{Zn}-\mathrm{O}$ which had a vibration characteristic of a simonkolleite structure. The O-H stretching bands are present at 2962 and $3019 \mathrm{~cm}^{-1}$ [36]. Several smaller peaks at $\sim 592, \sim 926, \sim 969, \sim 1077, \sim 1154, \sim 1466$ and $\sim 1778 \mathrm{~cm}^{-1}$, also indexed by an asterix, result from the multiple-phonon scattering process in the synthesized simonkolleite microplatelets.

The SEM micrographs in Fig. 4 clearly show the typical morphologies of the NF-G and the NF-G/simonkolleite composite. It can be seen from Fig. 4(a) that the 3D Ni-foam is a porous structure (pore size $\sim 0.15-2 \mathrm{~mm}$ ) with a smooth surface. Fig. 4(b) displays a representative sample of the as-grown graphene on struts of $\mathrm{Ni}$ foam. After the CVD process, graphene 


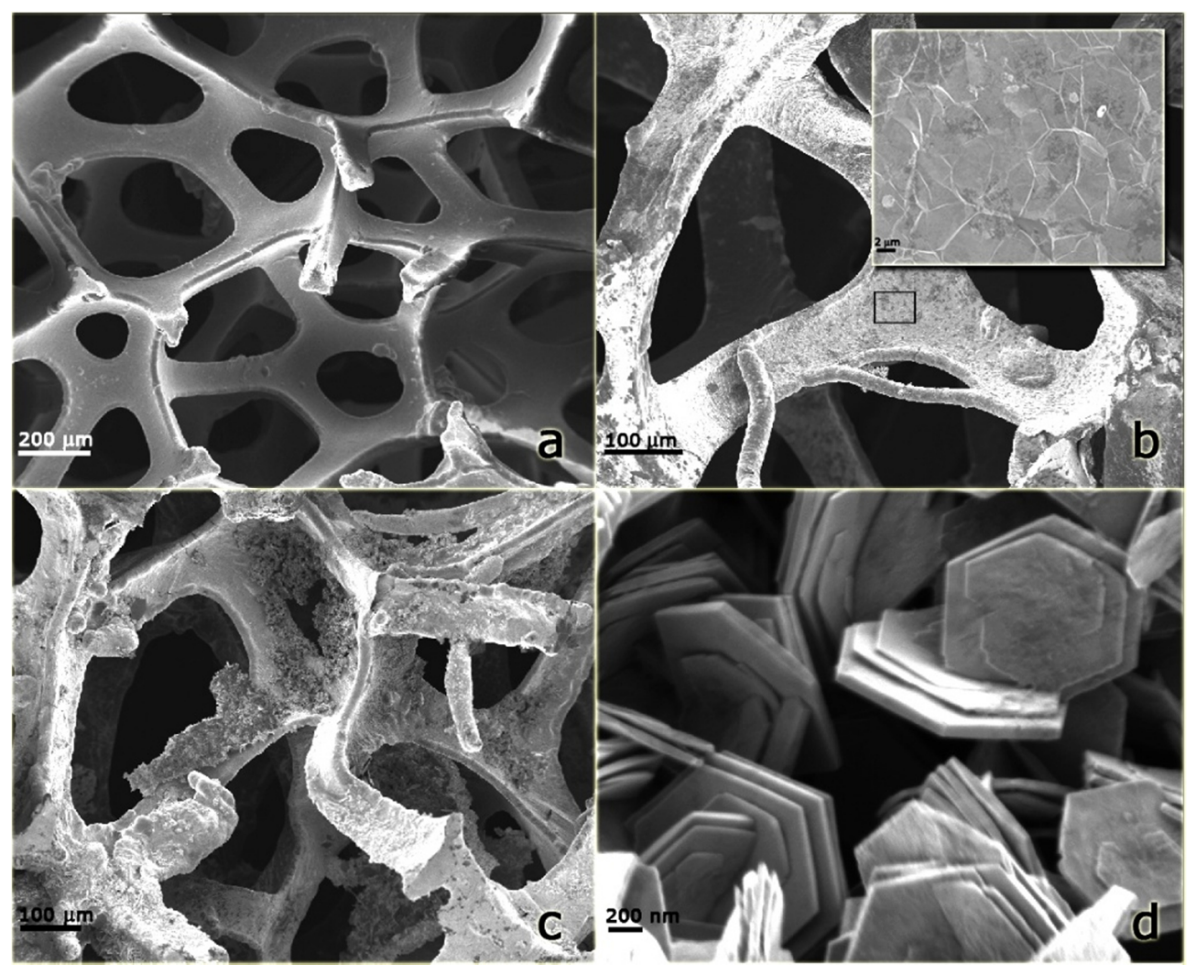

Figure 4: $\quad$ SEM micrographs of (a) bare 3D Ni foam; (b) NF-G - the inset in (b) shows a highmagnification view of the graphene deposited on the Ni foam; (c) NF-G/simonkolleite composite; (d) high-resolution image of the simonkolleite microplatelets

layers with different wrinkles were coated on the surface of the Ni-foam (inset in Fig. 4 (b)). The 3D configuration of the Ni-foam was preserved in all cases due to the structural template effect. In the NF-G/simonkolleite composite, microstructured simonkolleite is densely anchored onto both sides of the graphene surface (Fig. 4(c)). At higher magnification, it is observed that the simonkolleite microstructures are hexagonal and platelet-like (Fig. 4(d)). The diameter of the simonkolleite microplatelets is about $1.3-0.5 \mu \mathrm{m}$ and the thickness is about $60 \mathrm{~nm}$. In addition, there is no net spatial orientation either perpendicularly or parallel to the NF-G. The dense set of anisotropic microplatelets seems to grow faster along the basal plane and slower in the transversal direction, as shown in Fig. 4(d). It seems from the SEM results that the growth is denser in the basal direction at the very early stages, when the particles can be observed to be more flake-like. This could imply a growth mechanism similar to that of the $\mathrm{ZnO}$ nano/microscaled rods synthesized by a similar hydrothermal procedure [29]. If so, the growth mechanism should be a Frank-van der Merwe-driven process as well. Indeed, as supported by the high-resolution TEM image shown in Fig. 5(a), 
one can distinguish flake-like structures with quasi-sharp edges on top of each other within the basal planes, as indicated by the arrows. Consequently, the growth mechanism is likely to be driven by a Frank-van der Merwe process. Fig. 5(b) shows the SAED pattern of the simonkolleite microplatelets. It indicates the very high degree of crystallinity of the platelets with a net hexagonal symmetry and a possibly crystallographic preferential orientation. This crystallinity indicates that the plate-like $\mathrm{Zn}_{5}(\mathrm{OH})_{8} \mathrm{Cl}_{2} \cdot \mathrm{H}_{2} \mathrm{O}$ possessed a smooth surface.

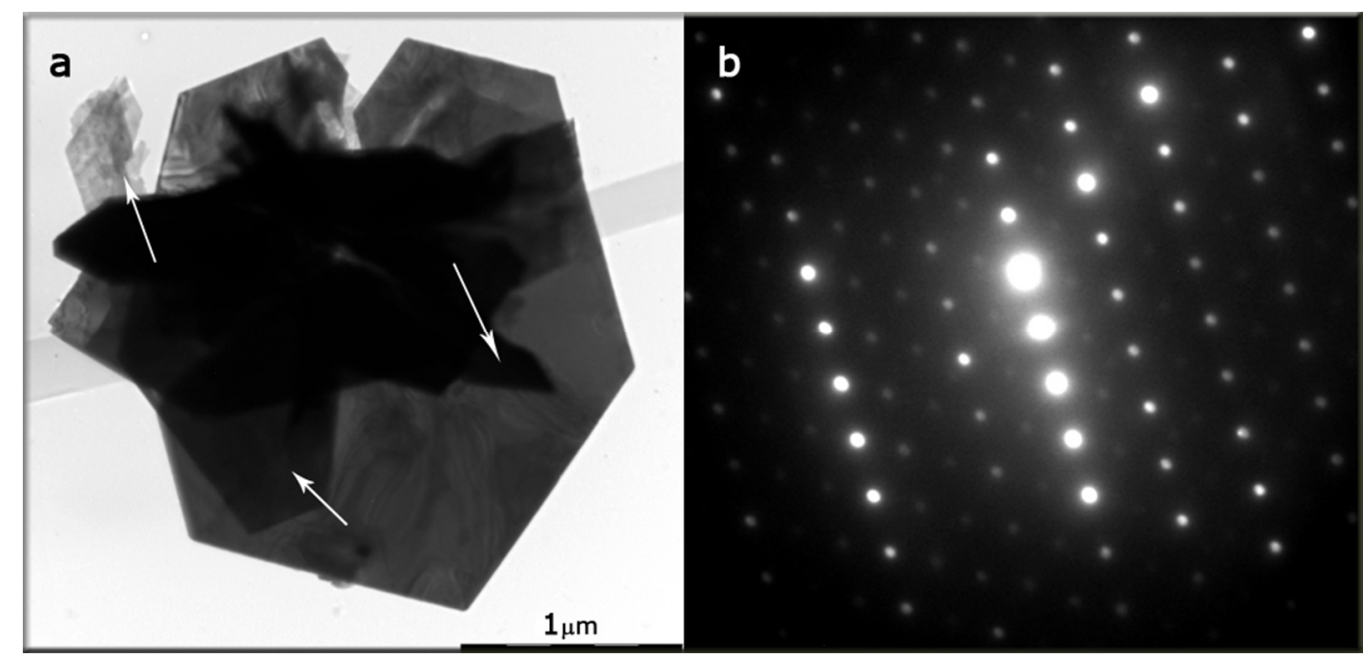

Figure 5: $\quad$ (a) Transmission electron micrographs (TEM) of a single simonkolleite microplatelet - arrows show the flake-like simonkolleite; (b) corresponding selected area electron diffraction (SAED) pattern of the simonkolleite microplatelets

To determine the electrochemical properties of the NF-G/simonkolleite composite we performed cyclic voltammetry $(\mathrm{CV})$ measurements using a three-electrode configuration. Fig. 6(a) compares the CV curves of NF, NF-G, NF-simonkolleite and the NF-G/simonkolleite composite (with mass ratio of graphene to simonkolleite 34:66) measured in a potential window of $0-0.5 \mathrm{~V}$ at scan rate of $25 \mathrm{mV} \mathrm{s}^{-1}$ in $2.0 \mathrm{M} \mathrm{KOH}$ electrolyte. NF itself showed very poor CV measurements and the NF-G electrode measured under the same conditions exhibited low-intensity current peaks due to the redox reaction of the nickel foam in the electrolyte [37], and also to the quasi-super hydrophobicity which is attributed to poor surface wetting and thus the reduced accessibility and utilisation of the available surface area [38]. The CV curve of the NF-simonkolleite foam in Fig 6(a) has an illdefined shape. The reason for this could be two-fold: (1) there may have been an increase in the particle size of the simonkolleite owing to aggregation, resulting in retarded transport of 
electrolyte ions, and (2) a fast scan rate may have induced a fast drop as a result of the high resistance of the simonkolleite microplatelets. Compared with the curve of the NFsimonkolleite, that of the NF-G/simonkolleite composite showed a much better mirror image with respect to the zero-current line and a more rapid current response on voltage reversal at each end-potential. These results indicate the much higher electrochemical reversibility of the NF-G/simonkolleite composite between 0 and $0.5 \mathrm{~V}$. This is probably due to the fact that graphene becomes entangled with simonkolleite and provides unobstructed pathways for $\mathrm{K}^{+}$ transport during the rapid charge-discharge process. In addition, the high conductivity of the graphene facilitates the transport of electrolyte ions during a rapid charge-discharge process.
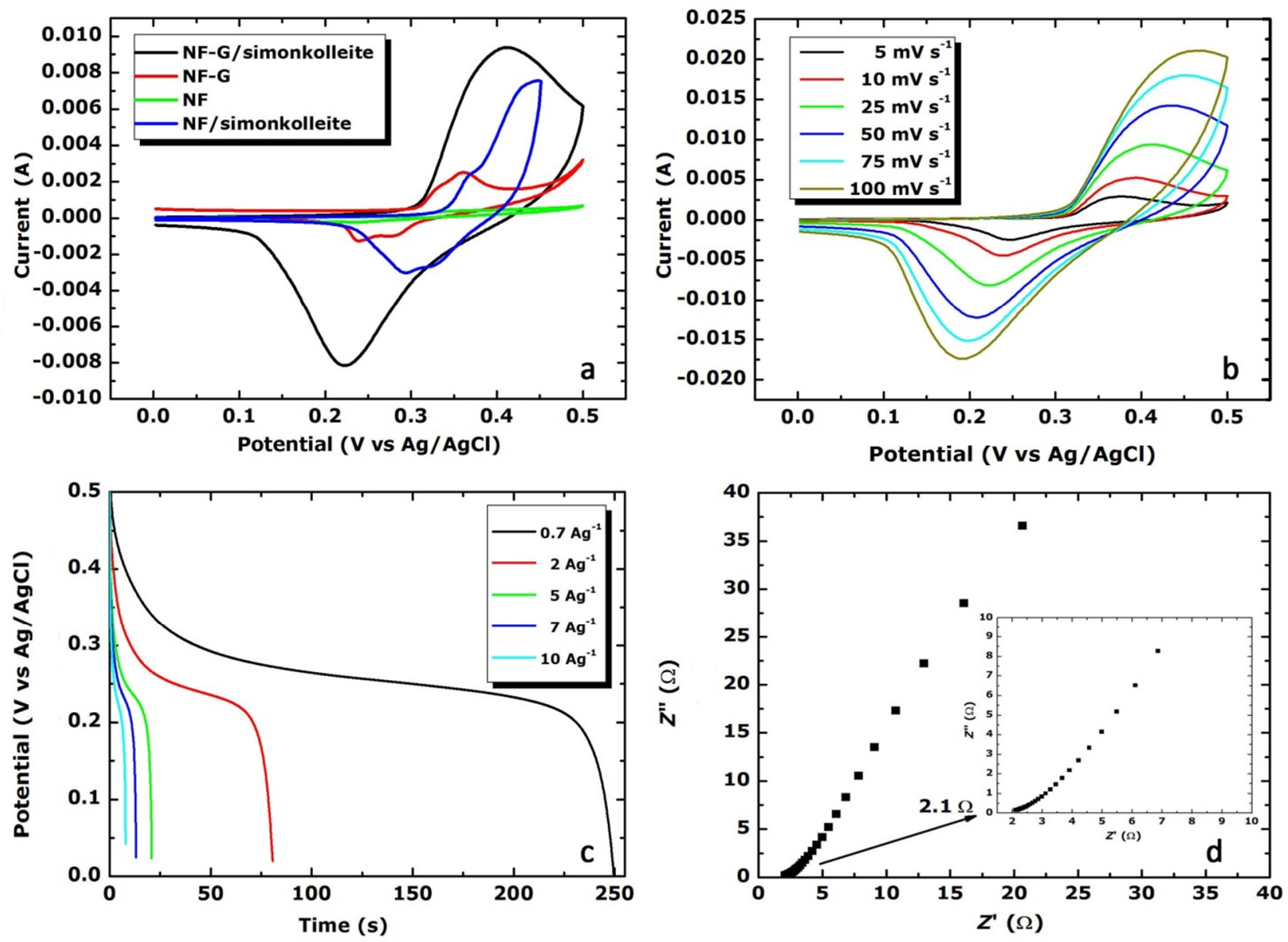

Figure 6: $\quad$ (a) $\mathrm{CV}$ curves of bare Ni foam (NF), NF-G, NF-simonkolleite and NF-G/simonkolleite composites at a scan rate of $25 \mathrm{mV} \mathrm{s}^{-1}$ in $2.0 \mathrm{M} \mathrm{KOH}$ electrolyte; (b) CV curves of the NF$\mathrm{G} /$ simonkolleite composite electrode at different scan rates; (c) galvanostatic charge-discharge curves of the NF-G/simonkolleite composite at different current densities; (d) Nyquist plot of the NF-G/simonkolleite composite - the inset in (d) shows the magnified plots in the highfrequency region 
The CV of the NF-G/simonkolleite composite electrode (Fig. 6(a)) shows a pair of Faradaic redox peaks $(\sim 0.23 \mathrm{~V}$ and $0.39 \mathrm{~V})$. These peaks result from the intercalation and deintercalation of $\mathrm{K}^{+}$from the electrolyte into $\mathrm{Zn}_{5}(\mathrm{OH})_{8} \mathrm{Cl}_{2} \cdot \mathrm{H}_{2} \mathrm{O}$ :

$$
\left[\mathrm{Zn}_{5}(\mathrm{OH})_{8} \mathrm{Cl}_{2} \cdot \mathrm{H}_{2} \mathrm{O}\right]_{\text {surface }}+\delta \mathrm{K}^{+}+\delta \mathrm{e}^{-} \underset{\text { charge }}{\stackrel{\text { discharge }}{\rightleftarrows}}\left[\mathrm{K}_{\delta} \mathrm{Zn}_{5}(\mathrm{OH})_{8} \mathrm{Cl}_{2} \cdot \mathrm{H}_{2} \mathrm{O}\right]_{\text {surface }}
$$

From the CV curve of the NF-G/simonkolleite composite one reversible electron-transfer process is observed. This is consistent with the reaction process mentioned above during the potential sweep of the simonkolleite $\left(\mathrm{Zn}_{5}(\mathrm{OH})_{8} \mathrm{Cl}_{2} \cdot \mathrm{H}_{2} \mathrm{O}\right)$ electrode. It demonstrates that the capacitance of the NF-G/simonkolleite composite is based on the charge storage mechanism of $\left(\mathrm{Zn}_{5}(\mathrm{OH})_{8} \mathrm{Cl}_{2} \cdot \mathrm{H}_{2} \mathrm{O}\right)$-based electrodes in mild electrolytes, which is ascribed to the rapid intercalation of alkali metal cations $\mathrm{K}^{+}$in the electrode during reduction and oxidation processes [39]. Fig. 6(b) shows the CV curves of the NF-G/simonkolleite composite electrode at different scan rates. The current response increased in accordance with increases in the scan rate, while no significant change in the shape of the CV curve was observed, indicating the good rate property of the NF-G/simonkolleite composite electrode.

To further evaluate the electrochemical capacitive performance of the NF-G/simonkolleite composite electrode, the galvanostatic charge-discharge curves were measured at different current densities within the potential range $0-0.5 \mathrm{~V}$ (Fig. 6(c)). The shape of the discharge curves does not show the characteristic of the pure double-layer capacitor but rather pseudocapacitance; this is in agreement with the $\mathrm{CV}$ curves which show redox peaks. The curves display two variations. First there is a linear variation of the time dependence of the potential (below $\sim 0.19 \mathrm{~V}$ ), indicating double-layer capacitance behaviour, which is caused by charge separation taking place between the electrode and the electrolyte. The other variation takes place in the potential range $0.5-0.19 \mathrm{~V}$, indicating typical pseudocapacitance behaviour resulting from the electrochemical adsorption/desorption or redox reaction at the interface between the electrode and the electrolyte [40]. The specific capacitance value $C_{\mathrm{s}}$ can be evaluated as:

$C_{\mathrm{s}}=I t / \Delta V m$

where $I$ is the charge-discharge current (A), $t$ is the discharge time (s), $\Delta V$ is the potential window (V), and $m$ is the mass (g) of the active NF-G/simonkolleite composite. 
Based on Equation (6), the values of the specific capacitance calculated from the discharge curves for the NF-G/simonkolleite composite are 350, 325.6, 212, 187 and $164 \mathrm{Fg}^{-1}$ at current densities of $0.7,2,5,7$ and $10 \mathrm{Ag}^{-1}$ respectively. This demonstrates that the NF-G/simonkolleite electrode obtained possesses a high and stable specific capacitance at high charge-discharge rates. This feature is very important for electrode materials to provide a high power density.

EIS is a very powerful tool used to investigate the electrochemical characteristics of the electrode/electrolyte interface using a Nyquist plot, which is a representation of the real and imaginary parts of the impedance in a sample [41]. The Nyquist plot of the NF-G/simonkolleite composite is shown in Fig. 6(d). The intercept on the X-axis in the high frequency region represents the intrinsic ohmic resistance of the internal resistance or equivalent series resistance (ESR) of the electrode material and the electrolyte [42]. The ESR value that was obtained from Fig. 6(d) for the NF-G/simonkolleite composite was $2.1 \Omega$ in 2 M KHO aqueous electrolyte, which is less than that of the NF-G (4.8 $\Omega$ ). In the Nyquist plot, the slope at low frequencies can be used to evaluate the capacitive behaviour of the electrode [43]. The nearly vertical slope of the NF-G/simonkolleite composite suggests that it has almost ideal capacitive behaviour.

For practical applications, the cycling/life stability of the NF-G/simonkolleite composite was studied. Fig. 7 shows that $\sim 87 \%$ of the initial specific capacitance is preserved after 500 continuous charge-discharge cycles at the high current density of $5 \mathrm{Ag}^{-1}$. This is an indication that the prepared NF-G/simonkolleite composite electrode material has long-term electrochemical stability and a high degree of charge-discharge reversibility. The excellent pseudocapacitive behaviour and high cycling stability can be attributed to the following: (1) graphene can provide a high electrical conductivity and a high specific surface area, allowing rapid and effective ion charge transfer and electron transport; (2) simonkolleite $\left(\mathrm{Zn}_{5}(\mathrm{OH})_{8} \mathrm{Cl}_{2} \cdot \mathrm{H}_{2} \mathrm{O}\right)$ microplatelets with excellent electrochemical activity and reversibility are grown directly on the graphene, and the chemical bonding that takes place between the simonkolleite microplatelets and the graphene favours electrochemical stability; (3) the graphene is deposited directly on the $\mathrm{Ni}$-foam collector, which avoids increasing the contact resistance between the electrode and the collector. 


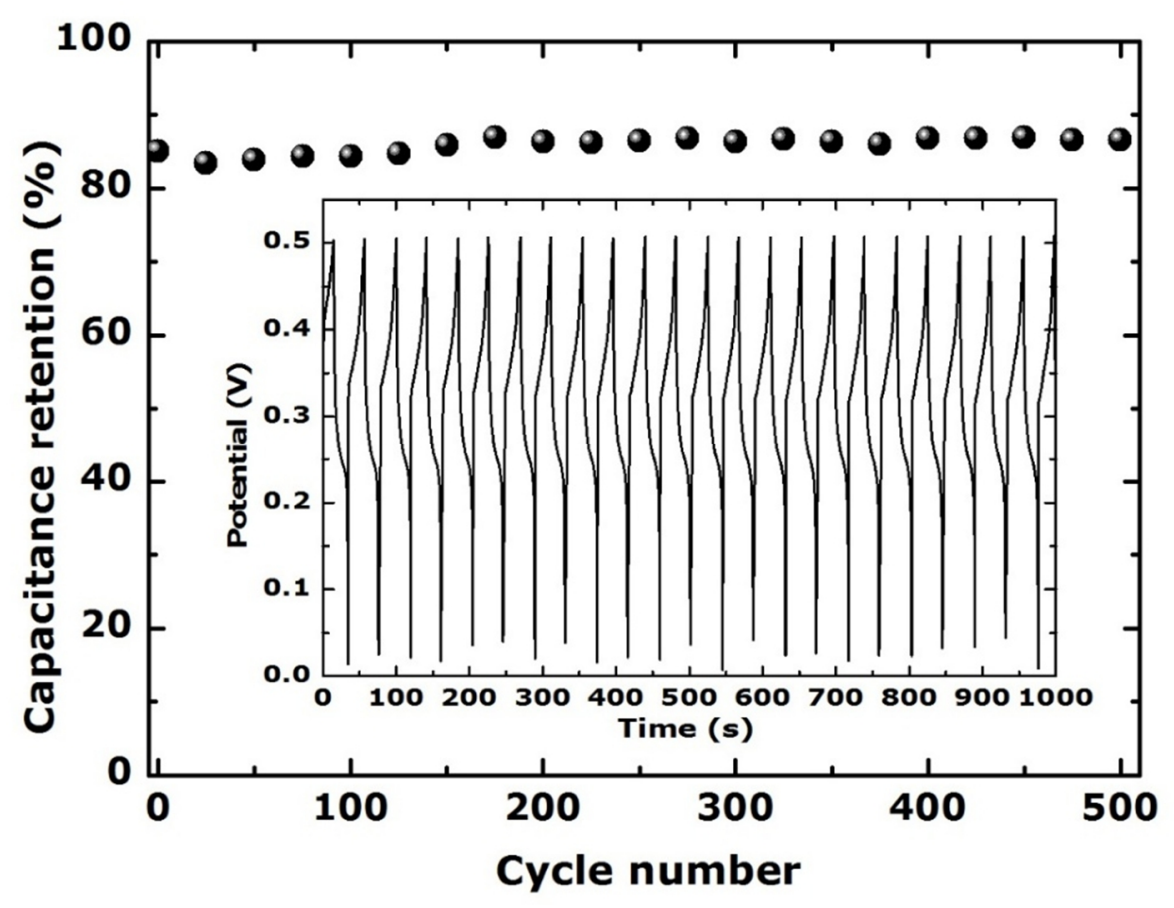

Figure 7: $\quad$ Cycle performance of the NF-G/simonkolleite composite at the current density of $5 \mathrm{Ag}^{-1}$ in 2.0 M KOH solution. The inset shows the charge-discharge profile for the NF-G/simonkolleite composite

\section{Conclusion}

Simonkolleite $\left(\mathrm{Zn}_{5}(\mathrm{OH})_{8} \mathrm{Cl}_{2} \cdot \mathrm{H}_{2} \mathrm{O}\right)$ microplatelets were successfully deposited on Ni foamgraphene by the aqueous chemical growth method. The composite material exhibits excellent performance as an electrode for supercapacitors owing to its unique $3 \mathrm{D}$ architecture, the electrochemical properties of simonkolleite, the extraordinary electrical and mechanical properties of graphene, and the synergistic integration of the two types of nanomaterial. The results discussed in this paper indicate that this nano-electrode possesses relatively high specific capacitance and long-term cycling stability, which offers great promise for applications in composite supercapacitors.

\section{Aknowledgments}

This work was financially supported by the Vice-Chancellor of the University of Pretoria and the National Research Foundation (NRF) of South Africa. 


\section{References}

1. Miller JR, Burke AF (2008) Electrochemical Capacitors: Challenges and Opportunities for Real-World Applications. Electrochem. Soc Interf 17:53-57

2. Masarapu C, Zeng HF, Hung KH, Wei BQ (2009) Effect of temperature on the capacitance of carbon nanotube supercapacitors. ACS Nano 3:2199-2206

3. Li GR, Feng ZP, Ou YN, Wu DC, Fu RW, Tong YX (2010) Mesoporous $\mathrm{MnO}_{2} /$ Carbon Aerogel Composites as Promising Electrode Materials for High-Performance Supercapacitors. Langmuir 26:2209-2213

4. Du X, Guo P, Song HH, Chen XH (2010) Graphene nanosheets as electrode material for electric double-layer capacitors. Electrochim Acta 55:4812-4819

5. Gao YY, Chen SL, Cao DX, Wang GL, Yin JL (2010) Electrochemical capacitance of $\mathrm{Co}_{3} \mathrm{O}_{4}$ nanowire arrays supported on nickel foam. J Power Sources 195:1757-1760

6. Yan J, Wei T, Qiao W, Shao B, Zhao Q, Zhang L, Fan Z (2010) Rapid microwaveassisted synthesis of graphene nanosheet $/ \mathrm{Co}_{3} \mathrm{O}_{4}$ composite for supercapacitors. Electrochim Acta 55:6973-6978

7. Wang DC, Ni WB, Pang H, Lu QY, Huang ZJ, Zhao JW (2010) Preparation of mesoporous $\mathrm{NiO}$ with a bimodal pore size distribution and application in electrochemical capacitors. Electrochim Acta 55:6830-6835

8. Pico F, Ibanez J, Rodenas L, Linares-Solano A, Rojas RM, Amarilla JM, Rojo JM (2008) Understanding $\mathrm{RuO}_{2} \cdot \mathrm{xH}_{2} \mathrm{O} /$ carbon nanofibre composites as supercapacitor electrodes. J. Power Sources 176:417-425

9. Li FH, Song JF, Yang HF, Gan SY, Zhang QX, Han DX, Ivaska A, Niu L (2009) Onestep synthesis of graphene/ $\mathrm{SnO}_{2}$ nanocomposites and its application in electrochemical supercapacitors. Nanotechnology 20:455602-455607

10. Yan J, Fan ZJ, Wei T, Qian WZ, Zhang ML, Wei F (2010) Fast and reversible surface redox reaction of graphene- $\mathrm{MnO}_{2}$ composites as supercapacitor electrodes. Carbon 48:3825-3833

11. Qu QT, Shi Y, Li LL, Guo WL, Wua YP, Zhang HP, Guan SY, Holze R (2009) $\mathrm{V}_{2} \mathrm{O}_{5} .0 .6 \mathrm{H}_{2} \mathrm{O}$ nanoribbons as cathode material for asymmetric supercapacitor in $\mathrm{K}_{2} \mathrm{SO}_{4}$ solution. Electrochem Commun 11:1325-1328

12. Stoller MD, Park S, Zhu Y, An J, Ruoff RS (2008) Graphene-Based Ultracapacitors. Nano Lett 8:3498-3502

13. Zhang LL, Zhou R, Zhao XS (2010) Graphene-based materials as supercapacitor electrodes. J Mater Chem 20:5983-5992

14. Lake JR, Cheng A, Selverston S, Tanaka Z, Koehne J, Meyyappan M, Che B (2012) Graphene metal oxide composite supercapacitor electrodes. J Vac Sci Technol B30:03D118

15. Shi W, Zhu J, Sim DH, Tay YY, Lu Z, Zhang X, Sharma Y, Srinivasan M, Zhang H, Hng HH, Yan Q (2011) Achieving high specific charge capacitances in $\mathrm{Fe}_{3} \mathrm{O}_{4} /$ reduced graphene oxide nanocomposites. J Mater Chem 21:3422-3427

16. Zhu J, Zhu T, Zhou X, Zhang Y, Lou XW, Chen X, Zhang H, Hng HH, Yan Q (2011) Facile Synthesis of Metal Oxide/Reduced Graphene Oxide Hybrids with High Lithium Storage Capacity and Stable Cyclability. Nanoscale 3:1084-1089

17. Wang H, Casalongue HS, Liang $\mathrm{Y}$, Dai $\mathrm{H}$ (2010) $\mathrm{Ni}(\mathrm{OH})_{2}$ nanoplates grown on graphene as advanced electrochemical pseudocapacitor materials. J Am Chem Soc 132:7472-7477

18. Li D, Muller MB, Gilje S, Kaner RB, Wallace GG (2008) Processable aqueous dispersions of graphene nanosheets. Nat Nanotechnol 3:101-105 
19. Dikin DA, Stankovich S, Zimney EJ, Piner RD, Dommett GH, Evmenenko G, Nguyen ST, Ruoff RS (2007) Preparation and characterization of graphene oxide paper. Nature 448:457-460

20. Chen H, Müller MB, Gilmore KJ, Wallace GG, Li D (2008) Mechanically strong, electrically conductive, and biocompatible graphene paper. Adv Mater 20:3557-3561

21. Dong X, Cao Y, Wang J, Chan-Park MB, Wang L, Huang W, Chen P (2012) Hybrid Structure of Zinc Oxide Nanorods and Three Dimensional Graphene Foam for Supercapacitor and Electrochemical Sensor Applications. RSC Advances 2:4364-4369

22. Chen ZP, Ren WC, Gao LB, Liu BL, Pei SF, Cheng HM (2011) Three-dimensional flexible and conductive interconnected graphene networks grown by chemical vapour deposition. Nat Mater 10:424-428

23. Li X, Cai W, An J, Kim S, Nah J, Yang D, Piner R, Velamakanni A, Jung I, Tutuc E, Banerjee SK, Colombo L, Ruoff RS (2009) Graphene Films with Large Domain Size by a Two-Step Chemical Vapor Deposition Process. Science 324:1312-1314

24. Kim KS, Zhao Y, Jang H, Lee SY, Kim JM, Kim KS, Ahn JH, Kim P, Choi JY, Hong BH (2009) Large-scale pattern growth of graphene films for stretchable transparent electrodes. Nature 457:706-710

25. Huang X, Qi XY, Boey F, Zhang H (2012) Graphene-based composites. Chem Soc Rev 41:666-686

26. Pérez C, Collazo A, Izquierdo M, Merino P, Nóvoa XR (2000) Electrochemical Impedance Spectroscopy Study of the Corrosion Process on Coated Galvanized Steel in a Salt Spray Fog Chamber. Corros 56:1220-1232

27. Zhu F, Persson D, Thierry D, Taxen C (2000) Formation of Corrosion Products on Open and Confined Zinc Surfaces Exposed to Periodic Wet/Dry Conditions. Corros 56:12561265

28. Hawthorne FC, Sokolova E (2002) Simonkolleite, $\mathrm{Zn}_{5}(\mathrm{OH})_{8} \mathrm{Cl}_{2}\left(\mathrm{H}_{2} \mathrm{O}\right)$, a decorated interrupted-sheet structure of the form $\left[\mathrm{M} \varphi_{2}\right]_{4}$. The Canadian Mineralogist 40:939-946.

29. Sithole J, Ngom BD, Khamlich S, Manikanadan E, Manyala N, Saboungi ML, Knoessen D, Nemutudi R, Maaza M (2012) Simonkolleite nano-platelets: Synthesis and temperature effect on hydrogen gas sensing properties. App Surf Sci 258:7839-7843.

30. Nowacki W, Silverman JN (1961) Die kristallstruktur von zinkhydroxychlorid II $\mathrm{Zn}_{5}(\mathrm{OH})_{8} \mathrm{Cl}_{2} \cdot 1 \mathrm{H}_{2} \mathrm{O}$. Z Kristallogr 115:21-51

31. Allmann R (1968) Verfeinerung der Struktur des Zinkhydroxidchlorids II $\mathrm{Zn}_{5}(\mathrm{OH})_{8}$ $\mathrm{Cl}_{2} \cdot 1 \mathrm{H}_{2} \mathrm{O} . \mathrm{Z}$ Kristallogr 126, 417-426

32. Wu YP, Wang B, Ma YF, Huang Y, Li N, Zhang F, Chen YS (2010) Efficient and largescale synthesis of few-layered graphene using an arc-discharge method and conductivity studies of the resulting films. Nano Res 3:661-669

33. Dong XC, Shi YM, Chen P, Ling QD, Huang W (2010) Aromatic molecules doping in single-layer graphene probed by raman spectroscopy and electrostatic force microscopy. J J Appl Phys 49:01AH04

34. Wei D, Mitchell JI, Tansarawiput C, Nam W, Qi M, Ye PD, Xu X (2013) Laser direct synthesis of graphene on quartz. Carbon 53:374-379

35. Reina A, Jia XT, Ho J, Nezich D, Son H, Bulovic V, Dresselhaus MS, Kong J (2009) Large Area, Few-Layer Graphene Films on Arbitrary Substrates by Chemical Vapor Deposition. Nano Lett 9:30-35

36. Bernard MC, Hugot-Le Goff A, Massinon D, Phillips N (1993) Underpaint corrosion of zinc-coated steel sheet studied by in situ raman spectroscopy. Corros Sci 35:1339-1349 
37. Xia X, Tu J, Mai Y, Chen R, Wang X, Gu C, Zhao X (2011) Graphene sheet/porous $\mathrm{NiO}$ hybrid film for supercapacitor applications. J Chem Eur 17:10898- 905

38. Brownson Dale AC, Figueiredo-Filho Luiz CS, Ji X, Gómez-Mingot M, Iniesta J, Fatibello-Filho O, Kampouris DK, Banks CE (2013) Freestanding three-dimensional graphene foam gives rise to beneficial electrochemical signatures within non-aqueous media. J Mater Chem A 1:5962-5972

39. Yan J, Fan Z, Wei T, Qian W, Zhang M, Wei F (2010) Fast and reversible surface redox reaction of graphene- $\mathrm{MnO}_{2}$ composites as supercapacitor electrodes. Carbon 48:3825-3833

40. Lang JW, Kong LB, Wu WJ, Liu M, Luo YC, Kang L (2009) A facile approach to the preparation of loose-packed $\mathrm{Ni}(\mathrm{OH})_{2}$ nanoflake materials for electrochemical capacitors. J Solid State Electrochem 13:333-340

41. Li X, Rong J, Wei B (2010) Electrochemical behavior of single-walled carbon nanotube supercapacitors under compressive stress. ACS Nano 4:6039-6049

42. Choi BG, Hong J, Hong WH, Hammond PT, Park H (2011) Facilitated ion transport in all-solid-state flexible supercapacitors. ACS Nano 5:7205-7213

43. Frackowiak E, Begguin F (2001) Carbon materials for the electrochemical storage of energy in capacitors. Carbon 39:937-950 